\title{
Distribution, pollution, bioaccumulation, and ecological risks of trace elements in soils of the northeastern Qinghai-Tibet Plateau
}

\author{
Leiming $\mathrm{Li}^{\mathrm{a}, \mathrm{b}, \mathrm{c}}$, Jun $\mathrm{Wu}^{\mathrm{a}, \mathrm{b}, \mathrm{c}, *}$, Jian $\mathrm{Lu}^{\mathrm{c}, \mathrm{d}}$, Xiuyun Min ${ }^{\mathrm{a}, \mathrm{b}, \mathrm{c}}$, Juan $\mathrm{Xu}^{\mathrm{e}}$, Long Yang ${ }^{\mathrm{b}}$ \\ ${ }^{\text {a }}$ Key Laboratory of Comprehensive and Highly Efficient Utilization of Salt Lake Resources, Qinghai Institute of Salt Lakes, Chinese Academy of Sciences, Xining, Qinghai \\ 810008, China \\ ${ }^{\mathrm{b}}$ Qinghai Provincial Key Laboratory of Geology and Environment of Salt Lakes, Xining, Qinghai 810008, China \\ ${ }^{\mathrm{c}}$ University of Chinese Academy of Sciences, Beijing 100049, China \\ ${ }^{\mathrm{d}}$ Key Laboratory of Coastal Environmental Processes and Ecological Remediation, Yantai Institute of Coastal Zone Research, Chinese Academy of Sciences, Yantai, \\ Shandong 264003, Chine \\ e State Key Laboratory of Marine Geology, Tongji University, Shanghai 200092, China
}

\section{A R T I C L E I N F O}

\section{Keywords:}

Trace element

The Qinghai-Tibet Plateau

Soil pollution

Ecological risk

Bioaccumulation

\begin{abstract}
A B S T R A C T
Environmental quality of the northeastern Qinghai-Tibet Plateau has attracted more attention due to increasing anthropogenic disturbance. Therefore, this study investigated the distribution, pollution, ecological risks, and bioaccumulation of 12 target heavy metals and 16 rare earth elements (REEs) in soils of this area. The average concentrations of target trace elements in soils ranged from $0.16(\mathrm{Hg})$ to $500.46(\mathrm{Cr}) \mathrm{mg} / \mathrm{kg}$. Pb caused more serious pollution than the other elements based on geo-accumulation index evaluation. $\mathrm{Hg}$ exhibited the strongest enrichment feature with the average enrichment factor of 8.41. Compare with modified contamination degree and pollution load index, Nemerow pollution index method obtained the most serious evaluation results that $45.67 \%$ and $16.54 \%$ of sampling sites possessed high and moderate pollution. Evaluation results of potential ecological risk index showed that trace elements in soils posed very high and considerable ecological risks in $34.65 \%$ and $7.09 \%$ of sampling sites, respectively. Mining area was the region with the most serious pollution and ecological risks. Average bioaccumulation factor $(B C F)$ values of target trace elements ranged from 0.05 (REEs) to 2.67 (Cr). Cr was the element that was easier to bio-accumulate in plants of the study area than the other target elements. It is in urgent need to take effective measures for controlling current pollution and potential ecological risks of trace elements in soils of the northeastern Qinghai-Tibet Plateau.
\end{abstract}

\section{Introduction}

Trace elements are generally non-biodegradable in natural environments with low concentrations and some of them are essential micro-nutrients (Milićević et al., 2017). Elevated concentrations of trace elements can cause serious environmental problems that not only threaten air, aquatic and soil ecosystems, but also cause food chain accumulation (Cong et al., 2010; Shao et al., 2016). Both natural and anthropogenic factors affect the distribution of trace elements and anthropogenic source is usually a main contributor (Lee et al., 2011). Trace elements including heavy metals and rare earth elements (REEs) have gained public attention in recent decades due to the relatively high concentrations detected in food, water, and soils (Li and Ji, 2017; Magesh et al., 2017; Yang et al., 2017).

Although "Heavy metals" might be a loose term to define metals and metalloids associated with possible pollution and potential toxicity (Duffus, 2002; Hodson, 2004), reports on pollution caused by "heavy metals" are continuously increasing. Moreover, heavy metal pollution has become a global problem because some metals are toxic and ready to accumulate in plants, animals, and humans (Yan et al., 2013; Wang et al., 2014a). Heavy metals are introduced to food chain to cause bioaccumulation and resultant bio-magnifications through diverse biogeochemical cycles (Yang et al., 2011; Zhang et al., 2016), causing a dangerous threat to humans because of their toxicity, persistence, nondestructible, and bioaccumulation (Abrahim and Parker, 2008; Mamat et al., 2016; Ding et al., 2017). Industrial processes, products/bi-products, mining, and discharges including untreated industrial wastes and wastewater are the sources of heavy metals (Avci and Deveci, 2013; Park and Choi, 2013).

REEs are lanthanide series which consist of a coherent group with

\footnotetext{
* Corresponding author at: Key Laboratory of Comprehensive and Highly Efficient Utilization of Salt Lake Resources, Qinghai Institute of Salt Lakes, Chinese Academy of Sciences, Xining, Qinghai 810008, China.

E-mail address: junwu@isl.ac.cn (J. Wu).
} 
similar chemical properties (Henderson, 1984; Loell et al., 2011). Background levels of REEs in soils are mainly influenced by weathering, parent materials, and pedogenetic processes (Zhang et al., 2009). Some studies have indicated a gradual increase of REEs in soils caused by anthropogenic inputs such as agriculture, mining and industrial activities (Hu et al., 2006; Kumari et al., 2015). The development of hightech industry promotes the use of REEs so as to increase the potential hazards of REEs to the ecosystems and human health (Kumari et al., 2015; Krishnakumar et al., 2016). Therefore, it is necessary to determine the concentrations of REEs in the natural environment in order to control the impacts of anthropogenic activity to the environment.

Arising from the rapid social development, pollution and risks posed by trace elements have been determined by diverse methods (Liu et al., 2017b; Ramachandra et al., 2018). Several methods such as geo-accumulation index $\left(I_{g e o}\right)$, enrichment factor $(E F)$, pollution load index (PLI), modified degree of contamination $\left(m C_{d}\right)$, and potential ecological risk index $(R I)$ are widely employed to evaluate contamination and ecological risks of trace elements in soils and sediments (Wang et al., 2014b; Liu et al., 2018). Trace elements might bio-accumulate in the plants through interaction between soil-plant systems. Thus, bioaccumulation factor is also used to denote pollution (Jeelani et al., 2017; Liu et al., 2017a).

The Qinghai-Tibet Plateau is regarded as the area far from high population, urbanization, and industrialization. However, many studies have showed astonishing facts on environmental quality of this "pure land" in China (Wu et al., 2016, 2018a). Trace elements are detected in diverse matrices such as water, sediments, soils, and biota with relatively high concentrations (Luo et al., 2014; Wu et al., 2018a, 2018b; Xie et al., 2014). The northeastern Qinghai-Tibet Plateau is more populated and industrialized than the other parts. Therefore, the objective of this study is to identify the distribution, possible pollution, potential ecological risks, and bioaccumulation of trace elements in soils of the northeastern Qinghai-Tibet Plateau. The final aim of this study is to provide comprehensive and thorough insight on the trace elements in soils of the northeastern Qinghai-Tibet Plateau so as to put the basis for environmental protection of the similar high-elevation areas.

\section{Materials and methods}

\subsection{The study area, sampling sites, and field sampling strategies}

The study area is located in the northeastern Qinghai-Tibet Plateau with average elevation of $3152 \mathrm{~m}$. Field sampling was carried out during June 14th to June 29th, 2017. Topsoil $(0-20 \mathrm{~cm})$ and plant samples were collected from 127 sampling sites (Fig. S1). The sampling sites covered 6 kinds of functional zones including background area, agricultural and pastoral area, industrial area, mining area, salt-lake area, and urban area. Soil samples were collected, stored, and prepared according to $\mathrm{Wu}$ et al. (2018a) for the following analysis. Plant (Potentilla anserina L.) sample was collected using a stainless-steel shovel to obtain the whole plant as possible and stored in a large sampling bag. Plant samples were transported back to the laboratory and stored at $-80^{\circ} \mathrm{C}$.

\subsection{Chemical analysis}

\subsubsection{Soil analysis}

Soil $\mathrm{pH}$ and texture were measure using the same procedure and instruments of Wu et al. (2018a). X-Ray fluorescence (XRF) spectrometers Axios PW4400 (PANalytical B.V., Netherland) was used to analyze the contents of $\mathrm{Fe}$ in soils. Soil samples were digested using a microwave dissolution system (SINEO Microwave Chemistry Technology Co., China). The digestion procedures referred to Wu et al. (2018b). The digested soil samples were analyzed by an Agilent7900 inductively coupled plasma mass spectrometry (ICP-MS, Agilent Inc, USA) to determine the concentrations of 12 typical heavy metals including lead $(\mathrm{Pb})$, cadmium (Cd), chromium ( $\mathrm{Cr}$ ), nickel (Ni), zinc $(\mathrm{Zn})$, molybdenum (Mo), copper $(\mathrm{Cu})$, tin $(\mathrm{Sn})$, mercury $(\mathrm{Hg})$, cobalt (Co), antimony (Sb), and vanadium (V) as well as 16 REEs consisting of lanthanum (La), cerium (Ce), praseodymium (Pr), neodymium (Nd), samarium (Sm), europium (Eu), gadolinium (Gd), terbium (Tb), dysprosium (Dy), holmium (Ho), erbium (Er), thulium (Tm), ytterbium (Yb), Lutetium (Lu), scandium (Sc), and yttrium (Y).

\subsubsection{Plant analysis}

Potentilla anserina L., a common herbaceous plant grown in the Qinghai-Tibet Plateau, was selected as the target plant of this study. Plant samples (roots and aboveground parts) were thoroughly washed by running tap water to remove soil particles, then rinsed five times with ultra-pure Milli-Q water and blotted extra water with tissue paper. Next the plant samples were dried at $105^{\circ} \mathrm{C}$ for $0.5 \mathrm{~h}$ and $75^{\circ} \mathrm{C}$ for $72 \mathrm{~h}$. Dry plant tissues (root and aboveground part together) were grinded to fine powder in an agate mortar, put into sample bags, and stored in a dryer at room temperature till analysis.

The plant samples were digested in a mixture solution of $\mathrm{HNO}_{3}, \mathrm{HCl}$ and HF. Approximately $100 \mathrm{mg}$ of dry plant sample was digested with $5 \mathrm{~mL}$ of $65 \% \mathrm{HNO}_{3}, 3 \mathrm{~mL}$ of $37 \% \mathrm{HCl}$, and $1 \mathrm{~mL}$ of $65 \% \mathrm{HF}$ (Ayrault et al., 2001; Shen et al., 2018). The other digestion procedures for plant samples were same as those for soils.

\subsection{Evaluating pollution, ecological risks, and bioaccumulation of trace elements in soils}

\subsubsection{Pollution of trace elements in topsoils}

Five methods including $I_{g e o}, E F, P L I, m C_{d}$, and Nemerow pollution index $(P N)$ were adopted to evaluate pollution of trace elements in topsoils of the northeastern Qinghai-Tibet Plateau. The detailed information on calculation of $I_{g e o}, E F, P L I$, and $m C_{d}$ referred to previously published articles (Wu et al., 2018a, 2018b). The background concentrations of trace elements in soils used for calculating $I_{g e o}, E F, P L I$, $m C_{d}$, and $P N$ referred to MEPC (1990). The calculations of these indices were briefly shown as the followings:

$I_{g e o}=\log _{2} \frac{C_{m}^{i}}{1.5 \times C_{b}^{i}}$

$E F=\frac{\left(\frac{C_{m}^{i}}{R_{s m}}\right)}{\left(\frac{C_{b}^{i}}{R_{b}}\right)}$

$P L I=\left(\frac{C_{m}^{1}}{C_{b}^{1}} \times \frac{C_{m}^{2}}{C_{b}^{2}} \times \ldots \times \frac{C_{m}^{n}}{C_{b}^{n}}\right)^{\frac{1}{n}}$

$m C_{d}=\frac{\sum_{i=1}^{n} \frac{C_{m}^{i}}{C_{b}^{i}}}{n}$

where $C_{m}^{i}$ and $C_{b}^{i}$ are the measured concentration and background concentration of the ith target trace element in soils, respectively; $n$ is the number of the target trace elements; $R_{s m}$ and $R_{b}$ are the measured concentration of reference element in soil sample and background concentration of reference element in soil, respectively. Elements $\mathrm{Al}$, $\mathrm{Mn}, \mathrm{Fe}, \mathrm{Ti}$, or $\mathrm{Ca}$ can generally serve as the reference elements for calculation of $E F$ (Maanan et al., 2004). Considering Fe is an important major element in soils, this study used Fe as reference element to calculate $E F$ values of trace elements in soils.

Nemerow pollution index $(P N)$ is also applied to comprehensively evaluate soil/sediment quality (Chen et al., 2010; Huang et al., 2018). $P N$ is calculated by the following equation: 
$P N=\sqrt{\frac{\left(\frac{C_{m}^{i}}{C_{b}^{i}}\right)_{\text {mean }}^{2}+\left(\frac{C_{m}^{i}}{C_{b}^{i}}\right)_{\max }^{2}}{2}}$

where $\left(\frac{C_{m}^{i}}{C_{\mathrm{b}}^{i}}\right)_{\max }$ and $\left(\frac{C_{m}^{i}}{C_{\mathrm{b}}^{i}}\right)_{\text {mean }}$ refer to the maximal value and average value of $\left(\frac{C_{m}^{i}}{C_{\mathrm{b}}^{i}}\right)$ among all target trace elements.

\subsubsection{Ecological risk assessment}

Trace elements exert potential ecological risks to the soil systems. Therefore, this study also explored the ecological risks of soil trace elements using potential ecological risk index $(R I)$. The calculation of $R I$ referred to published articles (Wu et al., 2018a, 2018b) and was briefly listed as the following:

$R I=\sum_{i=1}^{n} T_{m}^{i} \times \frac{C_{m}^{i}}{C_{b}^{i}}$

Where $T_{m}^{i}$ stands for the toxic factor of the $i$ th target trace element. The toxic factors for heavy metals referred to Hakanson (1980) while those for REEs were set as 1 (Wu et al., 2018b).

\subsubsection{Bioaccumulation of trace elements}

Bioaccumulation factor $(B C F)$ was used to determine the potential transfer of trace elements from soils to plants (Alexander et al., 2006; Liang et al., 2013; Liu et al., 2015). BCF values of trace elements were obtained using the following equation:

$B C F_{i}=\frac{P_{m}^{i}}{C_{m}^{i}}$

where $P_{m}^{i}$ represents the concentration of the $i$ th target trace element in plant; $B C F_{i}$ is $B C F$ value of the $i$ th target trace element.

\subsection{Data processing}

Geographic information system (GIS) has been widely applied to discuss the distribution of various pollutants (Xu et al., 2016). Inverse Distance Weight (IDW) interpolation was used to develop the digital terrain model (DTM) for the target trace metals or indices. Data on concentrations, pollution, ecological risks, and $B C F$ values were processed by ArcGIS 10.3 (ESRI Corp., USA) to obtain the corresponding distribution maps.

\section{Results and discussion}

\subsection{Distribution of trace elements in soil of the study area}

The predominant soil type in the study area was sandy clay loam according to soil texture analysis. Most of the soil samples in the study area were alkaline with the maximal/average $\mathrm{pH}$ reaching 10.32/8.49, respectively.

The distribution of individual heavy metals showed element-specific feature and drastic spatial variation (Fig. 1). Most of heavy metals in soils of the study area possessed relatively high average concentrations which were generally higher than the corresponding background values. The average concentrations of $\mathrm{Ni}, \mathrm{Zn}, \mathrm{Sn}$ and $\mathrm{Sb}$ were 2-3 times their background values. The maximal concentrations of $\mathrm{Pb}, \mathrm{Cd}, \mathrm{Cr}$, and $\mathrm{Hg}$ reached $8257.61,49.94,37,483.20$, and $0.8 \mathrm{mg} / \mathrm{kg}$, being 7.18 , $9.05,6.88$, and 8.00 times the corresponding background values, respectively. According to Environmental Quality Standard for Soils of China (GB15618-1995), soil quality of approximately $20.47 \%$ (target metal: Cd)-92.91\% (target metal: Ni), 1.57\% (target metal: Ni)-72.44\% (target metal: Cd), and 0.00\% (target metal: $\mathrm{Hg}$ and $\mathrm{Cu}$ )-7.09\% (target metal: Cd) of the sampling sites were evaluated as Level I, II, and III or worse, respectively. Distribution of heavy metals in soils of different functional areas also illustrated remarkable variation (Fig. 1). The highest average concentrations of $\mathrm{Cu}, \mathrm{Cd}, \mathrm{Pb}, \mathrm{Sn}, \mathrm{Hg}$, and $\mathrm{Zn}$ existed in the mining area while those of $\mathrm{Cr}$, Co, and Ni occurred in the industrial area. The highest average concentrations of Mo, V and Sb existed in the salt-lake area, agricultural and pastoral area and background area, respectively. The maximal concentrations of Mo and V occurred in the salt-lake area while the highest concentration of $\mathrm{Sb}$ existed in agricultural and pastoral area (Fig. 1). Difference in concentrations of heavy metals in soils of various functional areas exhibited that anthropogenic activities might have important impacts on distribution of soil heavy metals.

The concentrations of REEs in soils varied from 49.88 to $322.83 \mathrm{mg} /$ $\mathrm{kg}$ with an average value of $178.61 \mathrm{mg} / \mathrm{kg}$ (Fig. 1). Except S-14, S-108 and S-109, concentrations of REEs in soils of the remaining sites exceeded $100 \mathrm{mg} / \mathrm{L}$. The average concentration of REEs reached $178.55 \mathrm{mg} / \mathrm{kg}$, slightly higher than the natural background value. The average concentrations of individual REEs followed the order of $\mathrm{Ce}>$ $\mathrm{La}>\mathrm{Nd}>\mathrm{Y}>\mathrm{Sc}>\mathrm{Pr}>\mathrm{Sm}>\mathrm{Gd}>\mathrm{Dy}>\mathrm{Er}>\mathrm{Yb}>\mathrm{Eu}>\mathrm{Ho}>$ $\mathrm{Tb}>\mathrm{Tm}>\mathrm{Lu}$. Ce was the dominant element among REEs with concentrations ranging from 17.09 to $112.43 \mathrm{mg} / \mathrm{kg}$ while $\mathrm{La}$ and $\mathrm{Nd}$ also contributed with significant proportion to the concentrations of total REEs with average concentrations of 31.04 and $26.95 \mathrm{mg} / \mathrm{kg}$, respectively. These three dominant elements all belonged to LREEs (light REEs). The concentrations of LREEs ranged from 35.88 to $237.77 \mathrm{mg}$ / $\mathrm{kg}$ with average value of $135.33 \mathrm{mg} / \mathrm{kg}$ while those of HREEs (heavy REEs) ranged from 14.00 to $85.06 \mathrm{mg} / \mathrm{kg}$ with average value of $43.28 \mathrm{mg} / \mathrm{kg}$. The average concentration of soil REEs in the industrial area, mining area, salt-lake area, and urban area reached 165.92, $174.85,169.23$, and $172.90 \mathrm{mg} / \mathrm{kg}$, respectively, all lower than that in the background area (Fig. 1). Both two sampling sites with relatively high concentrations of REEs ( $>300 \mathrm{mg} / \mathrm{kg}$ ) were located in the industrial area. It was assumed that anthropogenic activities especially industrial processes might make important contribution to accumulation of REEs in soil.

\subsection{Pollution by trace elements in topsoils of the study area}

\subsubsection{Geo-accumulation index $\left(I_{\text {geo }}\right)$ evaluation}

$I_{\text {geo }}$ values of different heavy metals significantly varied in different sites. Average $I_{\text {geo }}$ values ranged from $-0.88(\mathrm{Tm})$ to $3.11(\mathrm{~Pb})$ while the minimal and maximal $I_{\text {geo }}$ values were $-4.66(\mathrm{Hg})$ and $11.36(\mathrm{~Pb})$, respectively. Based on $I_{g e o}$ ranking criterion (Mïller, 1969), heavy metals including $\mathrm{Cr}, \mathrm{Ni}$, Co and $\mathrm{V}$ showed the similar trend that over $90 \%$ of the sampling sites were classified into uncontaminated level meanwhile metals $\mathrm{Zn}$, Mo and $\mathrm{Cu}$ exhibited the similar patterns with uncontaminated percentages of $88.19 \%, 85.83 \%$, and 82.68 , respectively (Table S1). Cd posed uncontaminated to moderately contaminated level in $64.57 \%$ of sampling sites while it exerted heavy or more serious pollution in $5.51 \%$ of sites. $\mathrm{Hg}$ posed uncontaminated level in $50.39 \%$ of sites while it exerted heavy or more serious pollution in $29.92 \%$ of sampling sites. Sb mainly posed un-pollution and unpollution to moderate pollution in sampling sites. Sn in soils mainly showed un-pollution to moderate pollution. $\mathrm{Pb}$ posed the most serious contamination in the study area, with moderate, moderate to heavy, heavy, heavy to extreme, and extreme pollution levels in $5.51 \%$, $64.57 \%, 22.05 \%, 2.36 \%$, and $5.51 \%$ of sampling sites, respectively. The elements with the serious pollution were consistent with those previously reported (Wu et al., 2018a). $I_{\text {geo }}$ of heavy elements in different functional areas also showed remarkable site-specific feature (Fig. 2a and b). Un-pollution to moderate pollution of Co mainly existed in industrial area while moderate or more serious pollution of $\mathrm{Ni}$ also occurred in this area. Un-pollution to moderate pollution or worse of $\mathrm{Cu}$ mainly existed in mining area. Moreover, heavy or more serious pollution of $\mathrm{Pb}$ mainly occurred in mining area meanwhile the most serious pollution of $\mathrm{Cd}$ and $\mathrm{Zn}$ also existed in this area. Pollution of heavy metals in soil mainly occurred in industrial and mining areas, illustrating that those anthropogenic activities might pose important 

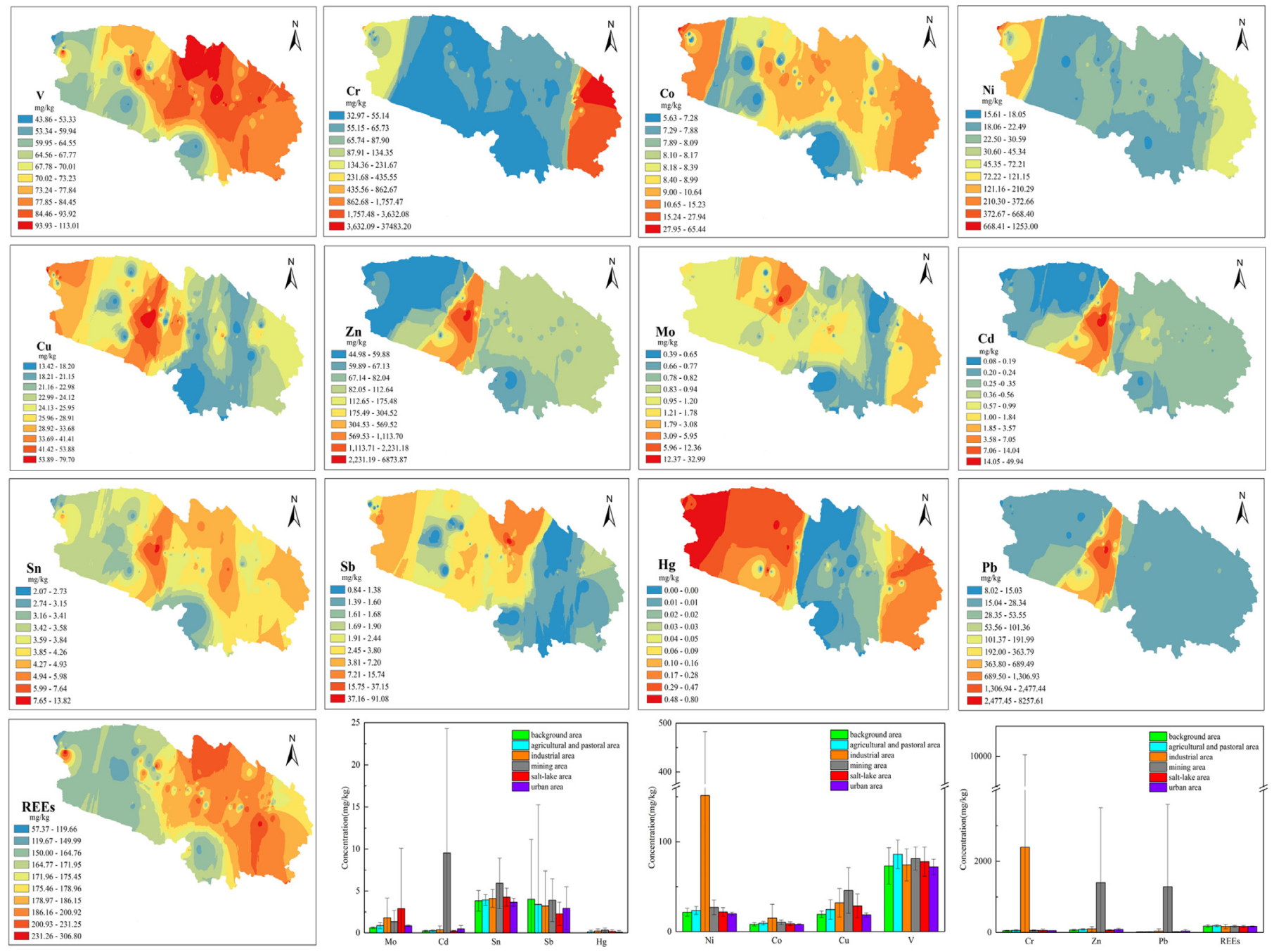

Fig. 1. Spatial distribution of individual trace elements in topsoils and average concentrations of target elements in soils of different functional areas.

influences to soil pollution.

Element Lu did not cause pollution in all sites according to $I_{\text {geo }}$ classification criterion while the rest of REEs did not induce pollution in over $90 \%$ of sites (Table S1), illustrating that REEs in soils might not do harm to the ecosystems. Except that Eu posed moderate pollution in $0.79 \%$ of sampling sites, the remaining REEs in soils exerted un-pollution or un-pollution to moderate pollution. The evaluation results of REEs were same with those previous reported (Wu et al., 2018b). Based on $I_{\text {geo }}$ classification criterion, total REEs caused un-pollution to moderate pollution in salt-lake area while they did not induce pollution in the remaining areas (Fig. 2a).

\subsubsection{Enrichment of trace elements in topsoils}

$E F$ values of heavy metals in topsoils ranged from $0(\mathrm{Hg})$ to 235.87 $(\mathrm{Pb})$ with average values in the range of $0.97(\mathrm{Co})-8.41(\mathrm{Hg})$, exhibiting significant spatial variation (Table S2). The elements with moderately severe enrichment were almost same with those previously reported (Wu et al., 2018a). Based on EF ranking criterion (Chester and Stoner, 1973), heavy metals including $\mathrm{Cr}$, Ni and Co showed the similar enrichment pattern that these metals did not enrich in soils of over $80 \%$ of sampling sites. Metals Zn, Mo and Sb exhibited no enrichment/minor enrichment in 55.91\%/37.80\%, 60.63\%/34.65\%, and 51.18\%/36.22\% of sampling sites, respectively. $\mathrm{Cu}$ and $\mathrm{V}$ exhibited the similar pattern with no enrichment/minor enrichment in $18.90 \% / 81.10 \%$ and $22.05 \% / 77.95 \%$ of sampling sites. $\mathrm{Pb}$ and $\mathrm{Cd}$ showed minor enrichment in $56.69 \%$ and $78.74 \%$ of sites while they exhibited severe or more serious enrichment in $3.94 \%$ and $6.30 \%$ of sampling sites, respectively. Sn mainly exhibited minor enrichment in $90.55 \%$ of sites. $\mathrm{Hg}$ in soils exhibited no enrichment in $48.03 \%$ of sampling sites while it showed severe or more serious enrichment in $33.07 \%$ of sampling sites. Interestingly, $\mathrm{Cd}, \mathrm{Pb}$ and $\mathrm{Zn}$ in soil sample collected from S-81 possessed the highest $I_{g e o}$ and $E F$ values while the rest of heavy metals did not exhibit similar pattern. Based on $E F$ classification criterion, heavy metals $\mathrm{Cu}$ and $\mathrm{V}$ exhibited no enrichment or minor enrichment in all functional areas (Fig. 2c and d). The most serious enrichment of $\mathrm{Cd}, \mathrm{Pb}$ and $\mathrm{Zn}$ mainly occurred in mining area while that of $\mathrm{Cr}$ and $\mathrm{Ni}$ occurred in industrial area. Enrichment of Mo mainly existed in salt-lake area. $\mathrm{Hg}$ showed the most serious enrichment in soils of industrial area, mining area, and salt-lake area. These results illustrated that enrichment of heavy metals in soils of the northeastern of Qinghai-Tibet Plateau might be affected by multiple factors.

REEs including La, Eu, Dy, Ho, Er, Tm, Yb, Lu, Sc and Y showed the similar enrichment pattern that these elements did not enrich in soils of over $60 \%$ of sampling sites while elements Ce, Pr, Nd, Sm, Gd and Tb showed minor enrichment in over $70 \%$ of sampling sites (Table S2). The average $E F$ values of REEs in different functional areas were all below 2 (Fig. 2c), illustrating that anthropogenic activities might not exert significant influence on enrichment of REEs in soils of the northeastern Qinghai-Tibet Plateau.

\subsubsection{Pollution evaluated using $m C_{d}, P L I$, and $P N$}

Pollution of trace elements in topsoils of the northeastern Qinghai- 

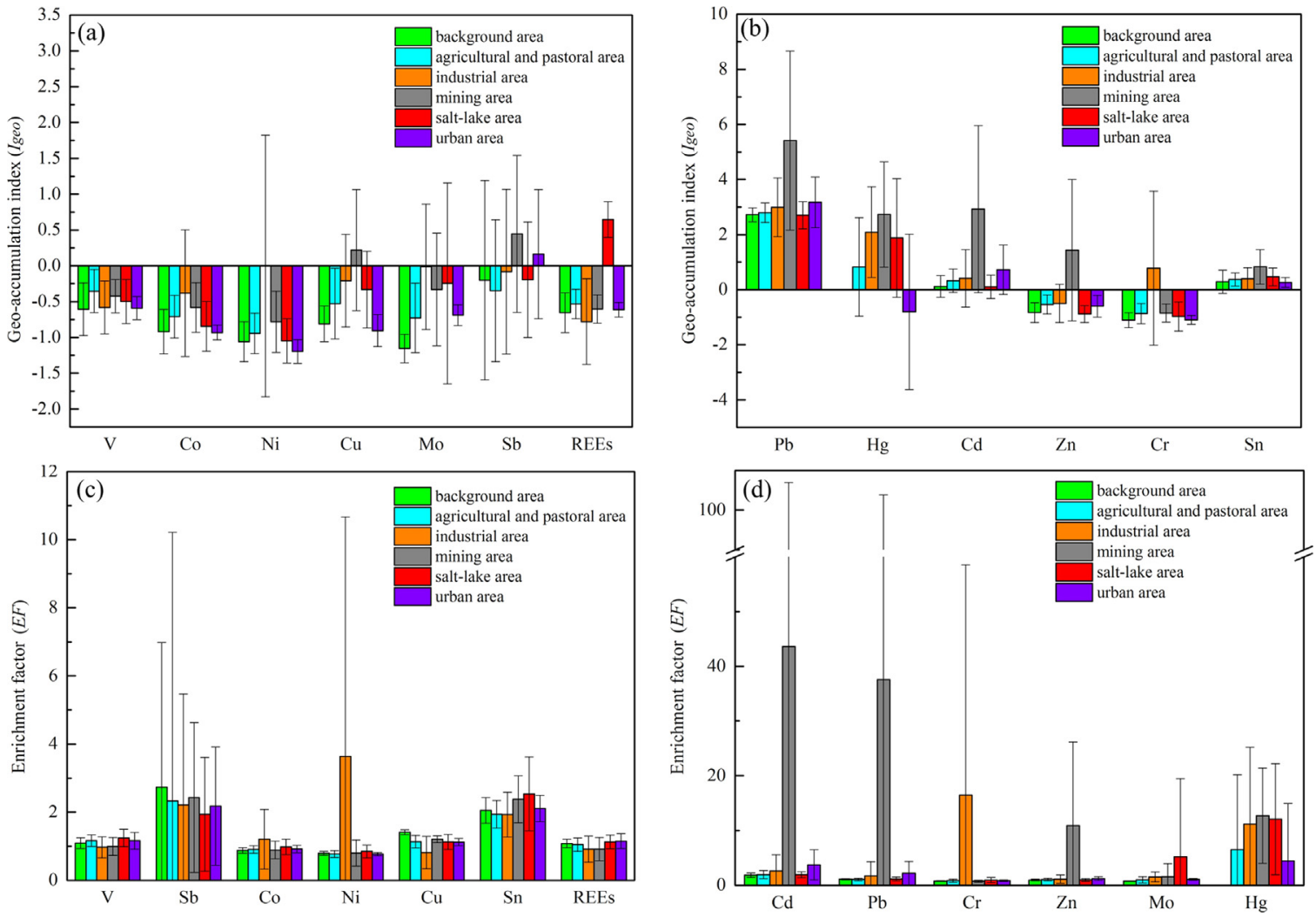

Fig. 2. Geo-accumulation index $\left(I_{g e o}\right)$ and enrichment factor $(E F)$ of trace elements in different areas.
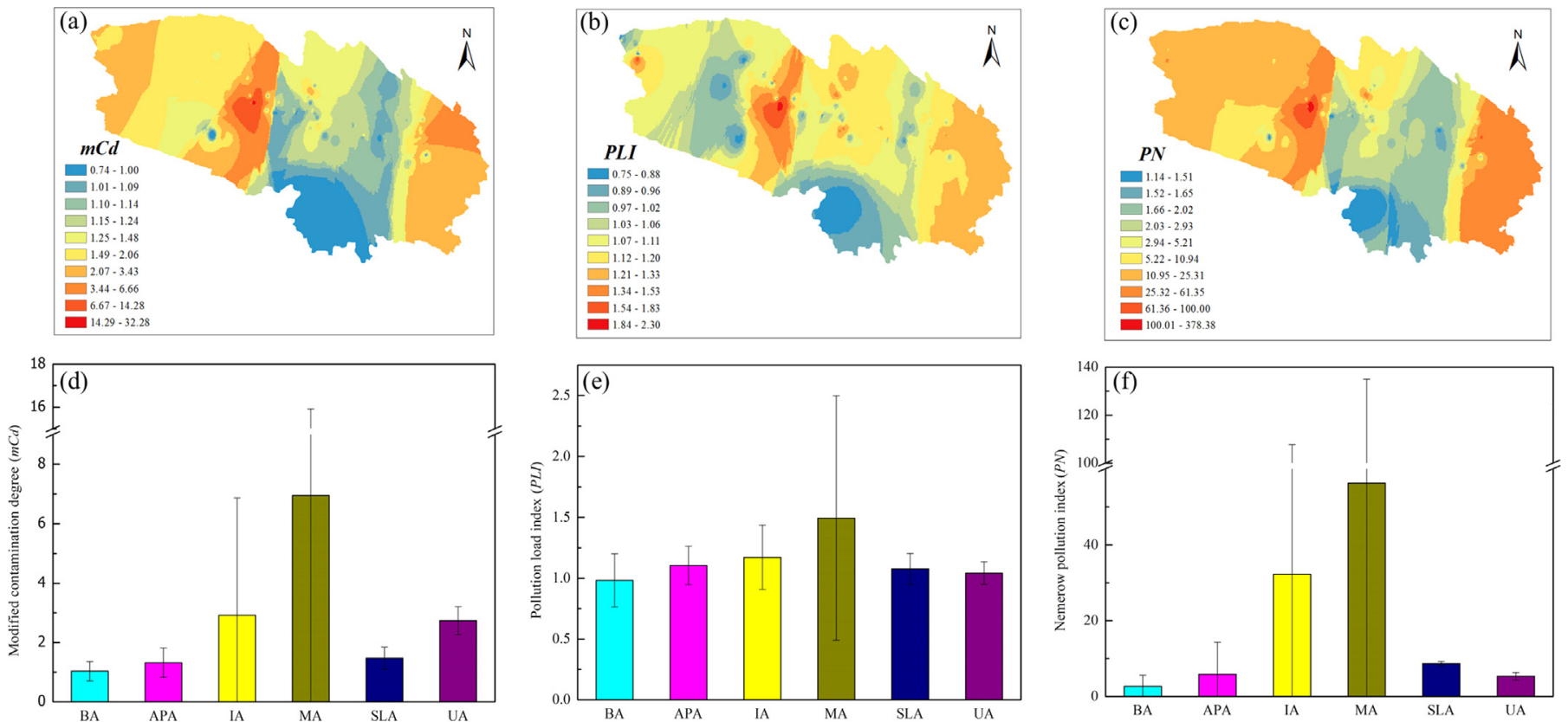

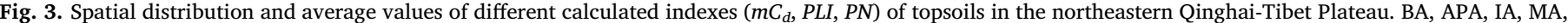
SLA, and UA referred to background area, agricultural and pastoral area, industrial area, mining area, salt-lake area, and urban area, respectively.

Tibet Plateau was comprehensively evaluated using $m C_{d}$ (Fig. 3a and d). Values of $m C_{d}$ ranged from 0.7 to 32.3 with the average of 2.2. Based on $m C_{d}$ ranking criterion (Abrahim and Parker, 2008), 81, 20, and 20 out of 127 sampling sites showed nil to very low, low, and moderate pollution levels, respectively. In contrast, approximately 1,3 , and 2 sampling sites showed high, very high, and extremely high pollution, respectively. Metals including $\mathrm{Cr}, \mathrm{Hg}, \mathrm{Zn}, \mathrm{Pb}$ and $\mathrm{Cd}$ were the main pollution contributors for sites with high or more serious pollution levels. Metals including $\mathrm{Cd}, \mathrm{Sn}, \mathrm{Sb}$ and $\mathrm{Hg}$ were the main pollution contributors for sites with moderate or less serious pollution. REEs did not contribute to soil pollution. According to the result of Wu et al. (2018a), Hg, Cd and Sn contributed to main $m C_{d}$ in many sites. Average $m C_{d}$ values of trace elements in different functional areas ranged from 1.0 in background area to 7.0 in mining area (Fig. 3d). Background area, agricultural and pastoral area, and salt-lake area showed nil to very low contaminated level while industrial area and urban area 
mainly illustrated moderate contaminated level. Mining area mainly exhibited moderate to extremely high contaminated levels. These results suggested that mining activities might be an important pollution source for trace elements.

$P L I$ also provided comparative information to assess the pollution of trace elements. The $P L I$ values in all sampling sites range from 0.8 in a nature reserve park to 2.3 in a lead/zinc mining region (Fig. 3b). Based on PLI ranking criterion (Seshan et al., 2010), approximately 3, 87, and 37 out of 127 sampling sites showed high, moderate, and low pollution levels, respectively. Elements including $\mathrm{Cr}, \mathrm{Cd}, \mathrm{Hg}$ and $\mathrm{Pb}$ were the main pollution contributors. Both heavy metals and REEs were taken to comprehensively evaluate the soil pollution of the study area using $m C_{d}$ and PLI so that pollution levels were less serious than those only assessed considering heavy metals (Wu et al., 2016, 2018a, 2018b). The average $P L I$ values of different functional areas ranged from 1.0 to 1.5 (Fig. 3e). Background area showed low pollution while agricultural and pastoral area, industry area, salt-lake area, and urban area mainly showed moderate pollution. Pollution in mining area was more serious than that in the remaining areas.

$P N$ values of trace elements in soils were unexpectedly high, ranging from 1.1 to 378.3 (Fig. 3c). Based on ranking criterion of $P N$ (Han et al., 2018), approximately 58, 21, and 48 sampling sites showed high, moderate, and low pollution, respectively. Elements including $\mathrm{Hg}, \mathrm{Cr}$, $\mathrm{Cd}$ and $\mathrm{Pb}$ mainly accounted for pollution evaluated by $P N$. The average $P N$ values varied from 2.6 in background area to 56.2 in mining area (Fig. 3f). Background area showed low to moderate pollution while the remaining areas mainly exhibited moderate to high pollution.

The presented data and analysis on trace elements in soils showed that some sampling sites of this study needed effective pollution control and remediation due to serious heavy metal pollution existing in these places. Mining area was the region with the most serious pollution based on the results so that mining activities should be carefully planned and managed to prevent the possible pollution. This study provided comprehensive information on distribution and pollution of trace elements in soils of the northeastern Qinghai-Tibet Plateau to put a basis for the effective environmental management, pollution control and prevention, future monitoring, and remediation in the high-elevation areas.

\subsection{Ecological risks posed by trace elements in topsoils of the study area}

$R I$ values of trace elements in soil ranged from 75.3 to $14,253.2$ (Fig. 4a). Based on RI ranking criterion (Hakanson, 1980), 44 out of 127 sampling sites exhibited very high ecological risk while 9 sites showed considerable ecological risk. In contrast, approximately 24 and 50 sites exhibited moderate and low ecological risks, respectively. $\mathrm{Hg}$ and $\mathrm{Cr}$ served as the dominant ecological risk contributors. $\mathrm{Hg}$ contributed over $50 \%$ of ecological risks to 49 sites with the contribution percentage ranging from $50.6 \%$ to $94.6 \%$. Cd accounted for over $50 \%$ ecological risks in 22 sites with the contribution percentage ranging from $50.0 \%$ to $76.7 \%$. Among the rest of trace elements, some metals such as $\mathrm{Cr}$ and $\mathrm{Sb}$ contributed over $50 \%$ ecological risks to several sites. The results of this study were consistent with those reported by Wu et al. (2018a). REEs induced very low ecological risks, which was similar with previous report (Wu et al., 2018b).

The average $R I$ values of different functional areas varied from 113.6 in background area to 3166.6 in mining area (Fig. 4b). Background area showed low ecological risks while agricultural and pastoral area, salt-lake area, and urban area showed considerable ecological risks. Industrial and mining areas exhibited very high ecological risks. Areas with relatively heavy pollution generally showed high potential ecological risks. Therefore, the industrial and mining areas deserved effective and urgent pollution control.

\subsection{Bioaccumulation of trace elements by wild plants in the study area}

\subsubsection{Distribution of trace elements in wild plants of the study area}

Concentrations of trace elements in plants of the northeastern Qinghai-Tibet Plateau also showed remarkable spatial variations (Fig. 5). The highest and average concentrations of $\mathrm{Cr}$ in plants reached 1939.00 and $204.04 \mathrm{mg} / \mathrm{kg}$. The maximal concentrations of $\mathrm{Pb}, \mathrm{Ni}, \mathrm{Zn}$, and $\mathrm{Cu}$ reached 260.055, 186.02, 608.20, and 165.49, respectively. Concentrations of REEs in plants ranged from 1.03 to $48.25 \mathrm{mg} / \mathrm{kg}$, similar with those of $\mathrm{V}$. Concentrations of $\mathrm{Hg}$ in plants were the lowest among all target trace elements with the average of $0.05 \mathrm{mg} / \mathrm{kg}$. The mean concentrations of the trace elements in wild plant grown in the study area followed the order of $\mathrm{Cr}>\mathrm{Zn}>\mathrm{Cu}>\mathrm{Ni}>\mathrm{V}>\mathrm{REEs}>$ $\mathrm{Pb}>\mathrm{Sn}>\mathrm{Co}>\mathrm{Mo}>\mathrm{Cd}>\mathrm{Sb}>\mathrm{Hg}$. The average concentrations of $\mathrm{Pb}, \mathrm{Cd}, \mathrm{Cr}, \mathrm{Ni}, \mathrm{Zn}, \mathrm{Co}, \mathrm{Sb}$ and $\mathrm{V}$ in plants grown in the study area exceeded the reported normal range compared with concentrations of trace elements in general plants (Kabata-Pendias, 2011), which was likely related to high concentrations of these elements in soils. The average concentration of $\mathrm{Cr}$ in plants of this study was significantly higher than that in other plants such as S. purpurea, K. Slenderbranch, and $K$. pygmaea growing in soils along the Qinghai-Tibet highway while the average concentration of $\mathrm{Cu}$ in plants of this study was similar with that previously reported (Zhang et al., 2016). The average concentrations of $\mathrm{Cr}, \mathrm{Co}, \mathrm{Ni}, \mathrm{V}$, and $\mathrm{Pb}$ in plants growing in the study area were significantly higher than those in the needles or organs/tissues of timberline forests in the eastern of Tibetan Plateau (Luo et al., 2013; Tang et al., 2014). Interestingly, the average concentrations of $\mathrm{Zn}$ and $\mathrm{Cu}$ in plants of this study were 2-3 times higher than those in vetch seeds of the Qinghai-Tibetan Plateau (Mao et al., 2015).

The average concentrations of trace elements in wild plants from
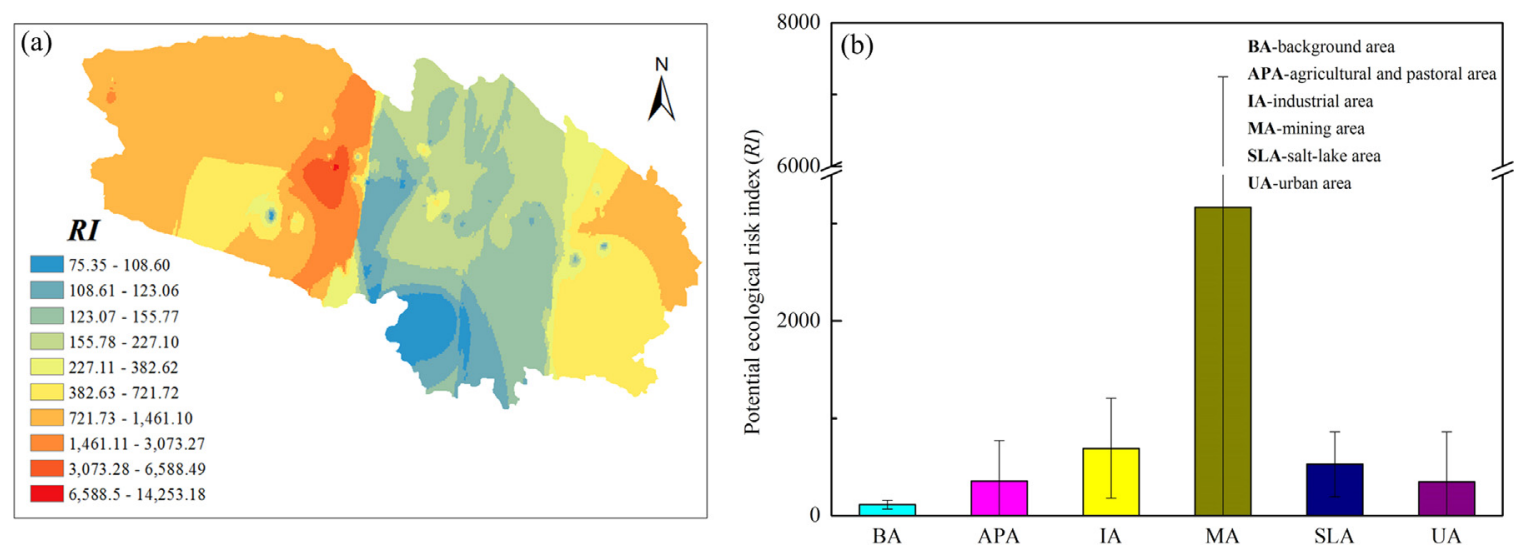

Fig. 4. Spatial distribution and average values of $R I$ in the northeastern Qinghai-Tibet Plateau. BA, APA, IA, MA, SLA, and UA referred to background area, agricultural and pastoral area, industrial area, mining area, salt-lake area, and urban area, respectively. 

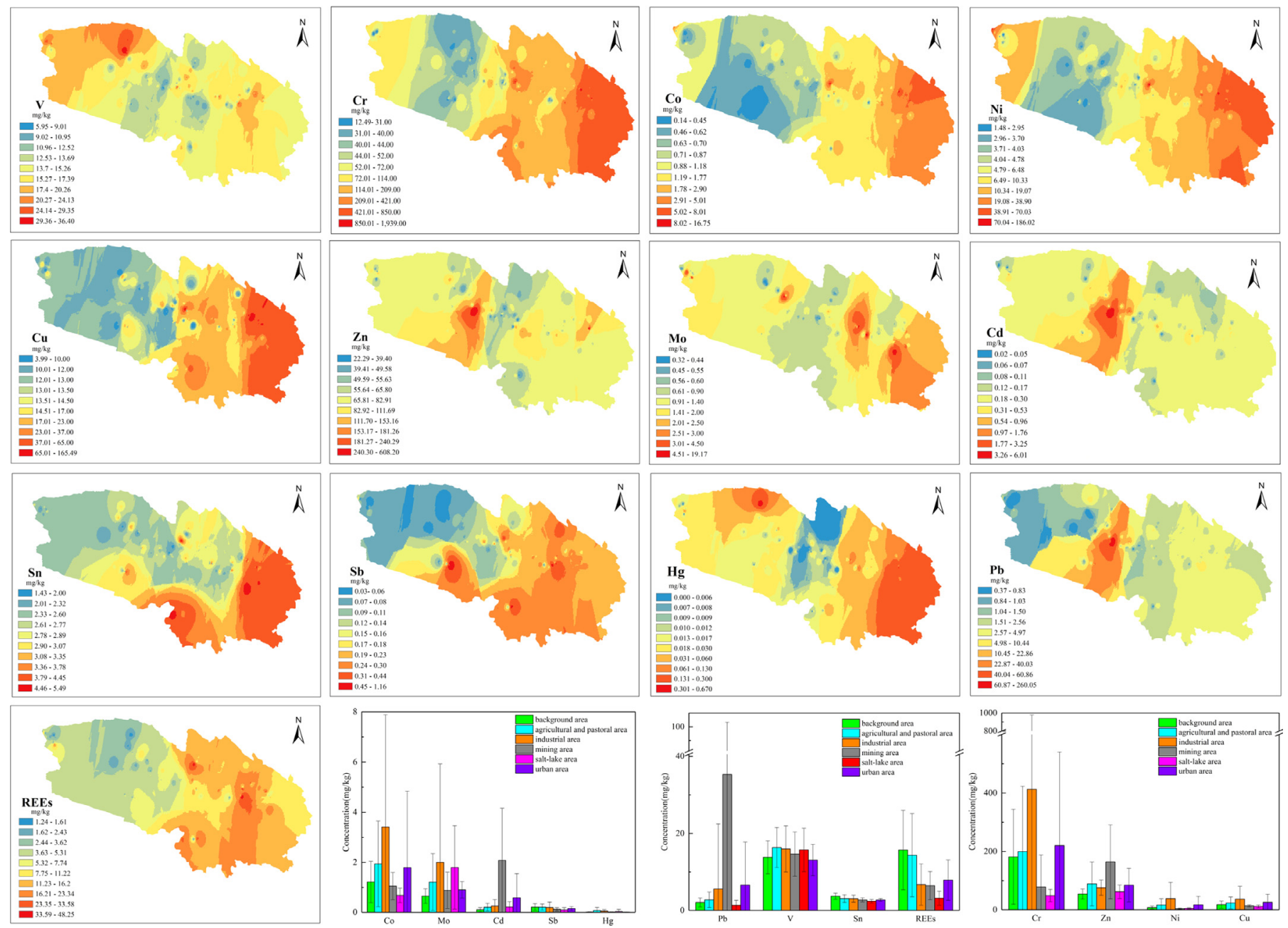

Fig. 5. Spatial distribution of individual trace elements in plants and average concentrations of target elements in plants of different functional areas.

different functional areas ranged from $0.01(\mathrm{Hg})$ to $412.89(\mathrm{Cr}) \mathrm{mg} / \mathrm{kg}$ (Fig. 5). Average concentrations of $\mathrm{Co}, \mathrm{Mo}, \mathrm{Cr}, \mathrm{Ni}$, and $\mathrm{Cu}$ in plants from industrial area were higher than those from the rest of areas. Average concentrations of $\mathrm{Cd}, \mathrm{Zn}$, and $\mathrm{Pb}$ in plants from mining area were higher than those from the remaining areas. Average concentrations of Sn and total REEs in plants from background area were higher than those from the other areas while average concentration of $\mathrm{V}$ in plants from agricultural and pastoral area was the highest compared with that in other areas. The results illustrated that some trace elements in industrial and mining area might negatively affect the wild plants in the northeastern Qinghai-Tibet Plateau.

\subsubsection{Bioaccumulation of trace elements in wild plants}

$B C F$ is generally capable of reflecting the uptake ability of the metals by plant. Therefore, this study used $B C F$ to investigate the bioaccumulation of trace elements in wild plants grown in the northeastern Qinghai-Tibet Plateau (Fig. 6). The BCF values of all target trace elements ranged from 0.00 to 17.87 . The average $B C F$ values of trace elements were in the range of 0.05 (REEs)-2.67 (Cr), and followed the order of $\mathrm{Cr}>\mathrm{Mo}>\mathrm{Cu}>\mathrm{Zn}>\mathrm{Cd}>\mathrm{Sn}>\mathrm{Ni}>\mathrm{Hg}>\mathrm{V}>\mathrm{Co}>\mathrm{Sb}>$ $\mathrm{Pb}>$ REEs. Compared with the other elements, $\mathrm{Cr}$ was easier to bioaccumulate in plants of the study area. The average $B C F$ values of Mo, $\mathrm{Cu}, \mathrm{Zn}, \mathrm{Cd}, \mathrm{Sn}$ and Ni were fairly high, illustrating that these metals had high mobile fraction in the soil to transfer into plants (Jeelani et al., 2017). The average $B C F$ value of $\mathrm{Hg}$ in the study area was much higher than that in Huludao City (Zhang et al., 2010) while the average $B C F$ value of Cd in the study area was significantly higher than that in Cd- contaminated vegetable farms around the Pearl River Delta (Hu et al., 2013). The average $B C F$ values of $\mathrm{V}, \mathrm{Co}, \mathrm{Sb}, \mathrm{Pb}$ and REEs were relatively low, indicating that it was relatively difficult for these elements to transfer between soils and plants (Liu et al., 2017a).

The average $B C F$ values of target elements in different functional areas varied significantly (Fig. 6). The average $B C F$ values of $\mathrm{Pb}, \mathrm{Co}, \mathrm{Sb}$, $\mathrm{V}$ and REEs were all under 0.3 in different functional areas while those of $\mathrm{Zn}, \mathrm{Cd}, \mathrm{Mo}, \mathrm{Cu}$ and $\mathrm{Sn}$ in different areas ranged from 0.45 to $1.60 \mathrm{Hg}$ easily accumulated in plants grown in salt-lake area while it did not to bio-accumulate in plants grown in background area. Ni easily accumulated in plants from industrial and urban area. Except salt-lake area, the average $B C F$ values of $\mathrm{Cr}$ in the remaining areas were higher than 1.0, showing high bioaccumulation. Effective control policy should be put forward because $\mathrm{Cr}$ was a highly toxic heavy metal.

\section{Conclusions}

The average concentrations of trace elements in soils of the study area ranged from $0.16(\mathrm{Hg})$ to $500.46(\mathrm{Cr}) \mathrm{mg} / \mathrm{kg}$. The maximal concentrations of $\mathrm{Pb}, \mathrm{Cd}, \mathrm{Cr}$, and $\mathrm{Hg}$ were over 6 times the corresponding background values, respectively. The average concentration of REEs reached $178.55 \mathrm{mg} / \mathrm{kg}$, slightly higher than the natural background value. Five methods were used to evaluate pollution of trace element in soils of study area. $\mathrm{Pb}$ posed the most serious contamination in the study area based on $I_{\text {geo }}$ evaluation, with moderate to heavy and heavy or more serious pollution levels in $64.57 \%$ and $29.92 \%$ of sampling sites, respectively. $\mathrm{Pb}$ and $\mathrm{Cd}$ showed minor enrichment in $56.69 \%$ and 

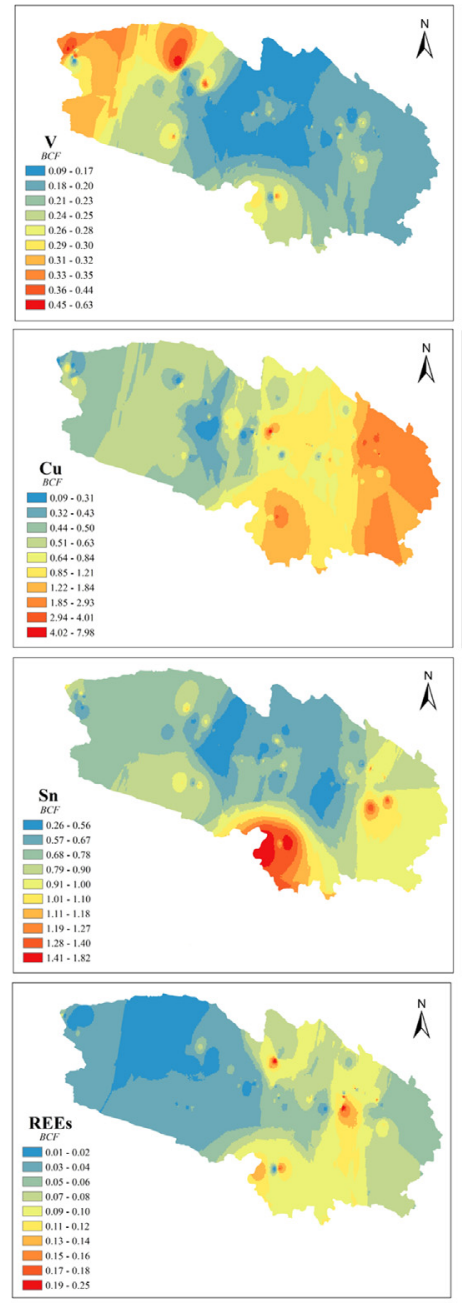
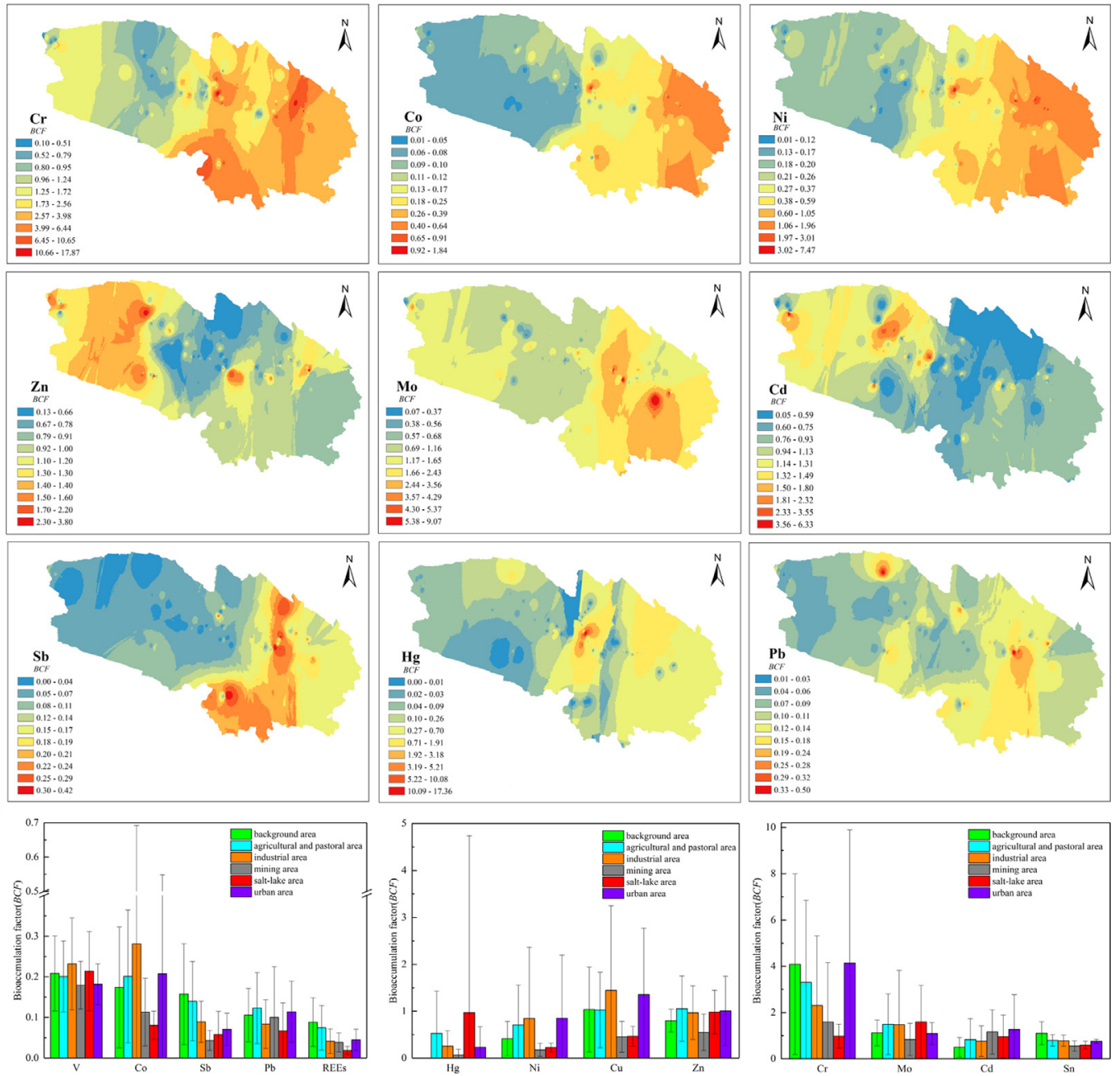

Fig. 6. Spatial $B C F$ distribution of individual trace elements and average $B C F$ values of target elements in different functional areas.

$78.74 \%$ of sites while they exhibited severe or more serious enrichment in $3.94 \%$ and $6.30 \%$ of sampling sites, respectively. Trace elements with high concentrations in soils and relatively serious pollution or enrichment mainly existed in mining and industrial areas. Modified contamination degree evaluation results showed that very high, high, and moderate pollution occurred in $2.36 \%, 0.79 \%$ and $15.74 \%$ of sampling sites, respectively. Pollution load index evaluation showed that moderate and high pollution existed in $68.50 \%$ and $2.36 \%$ of sampling sites. Nemerow pollution index results illustrated that high and moderate pollution occurred in $45.67 \%$ and $16.54 \%$ of sampling sites, respectively. Mining area was the region with the most serious pollution. Potential ecological risk indices posed by trace elements in soil ranged from 75.3 to $14,253.2$, showing that very high and considerable ecological risks existed in about $34.65 \%$ and $7.09 \%$ of sampling sites. Average $B C F$ values of target trace elements ranged from 0.05 (REEs) to $2.67(\mathrm{Cr})$. Cr was the element that was easier to bioaccumulate in plants of the study area than the other target elements. REEs in soils contributed to soil pollution much less than heavy metals and they exerted very low ecological risks. Therefore, effective management policy should be put forward to control the current pollution and potential risks of heavy metals in soils of the northeastern QinghaiTibet Plateau.

\section{Acknowledgements}

This work was financially supported by National Natural Science Foundation of China (Nos. 41671319 and 41877131), One Hundred
Talents Program of Chinese Academy of Sciences (Grant numbers of Y610061033 and Y629041021), Thousand Talents Plan of Qinghai Province (Y740171071), and Two-Hundred Talents Plan of Yantai (Y739011021). We also would like to thank the reviewers for their valuable comments and suggestions on the manuscript.

\section{Appendix A. Supplementary material}

Supplementary data associated with this article can be found in the online version at doi:10.1016/j.ecoenv.2018.09.110.

\section{References}

Abrahim, G.M.S., Parker, R.J., 2008. Assessment of heavy metal enrichment factors and the degree of contamination in marine sediments from Tamaki Estuary, Auckland, new Zealand. Environ. Monit. Assess. 136, 227-238.

Alexander, P.D., Alloway, B.J., Dourado, A.M., 2006. Genotypic variations in the accumulation of $\mathrm{Cd}, \mathrm{Cu}, \mathrm{Pb}$ and $\mathrm{Zn}$ exhibited by six commonly grown vegetables. Environ. Pollut. 144 (3), 736-745.

Avci, H., Deveci, T., 2013. Assessment of trace element concentrations in soil and plants from cropland irrigated with wastewater. Ecotoxicol. Environ. Saf. 98, 283-291.

Ayrault, S., Bonhomme, P., Carrot, F., Amblard, G., Sciarretta, M.D., Galsomiès, L., 2001. Multianalysis of trace elements in mosses with inductively coupled plasma-mass spectrometry. Biol. Trace Elem. Res. 79 (2), 177-184.

Chen, T.-R., Yu, K.-F., Li, S., Price, G.J., Shi, Q., Wei, G.-J., 2010. Heavy metal pollution recorded in Porites corals from Daya Bay, northern South China Sea. Mar. Environ. Res. 70, 318-326.

Chester, R., Stoner, J.H., 1973. Pb in particulates from the lower atmosphere of the eastern Atlantic. Nature 245, 27-28.

Cong, Z., Kang, S., Zhang, Y., Li, X., 2010. Atmospheric wet deposition of trace elements to central Tibetan Plateau. Appl. Geochem. 25, 1415-1421. 
Ding, Q., Cheng, G., Wang, Y., Zhuang, D., 2017. Effects of natural factors on the spatial distribution of heavy metals in soils surrounding mining regions. Sci. Total Environ. 578, 577-585.

Duffus, J.H., 2002. Heavy metals-a meaningless term? Pure Appl. Chem. 74, 793-807. (Available on the IUPAC website at). 〈http://www.iupac.org/publications/pac/ 2002/7405/7405 ×0793.html>.

Hakanson, L., 1980. An ecological risk index for aquatic pollution control.a sedimentological approach. Water Res. 14, 975-1001.

Han, W., Gao, G., Geng, J., Li, Y., Wang, Y., 2018. Ecological and health risks assessment and spatial distribution of residual heavy metals in the soil of an e-waste circular economy park in Tianjin, China. Chemosphere 197, 325-335.

Henderson, P., 1984. Rare Earth Element Geochemistry 22. Elsevier, pp. 242-243.

Hodson, M.E., 2004. Heavy metals_geochemical bogey men? Environ. Pollut. 129, 341-343.

Hu, J., Wu, F., Wu, S., Sun, X., Lin, X., Wong, M.H., 2013. Phytoavailability and phytovariety codetermine the bioaccumulation risk of heavy metal from soils, focusing on Cd-contaminated vegetable farms around the pearl river delta, China. Ecotoxicol. Environ. Saf. 91 (2), 18-24.

Hu, Z., Haneklaus, S., Sparovek, G., Schnug, E., 2006. Rare earth elements in soils. Commun. Soil Sci. Plant Anal. 37, 1381-1420.

Huang, Y., Chen, Q., Deng, M., Japenga, J., Li, T., Yang, X., He, Z., 2018. Heavy metal pollution and health risk assessment of agricultural soils in a typical peri-urban area in southeast China. J. Environ. Manag. 207, 159-168.

Jeelani, N., Zhu, Z., Wang, P., Zhang, P., Song, S., Yuan, H., An, S., Leng, X., 2017. Assessment of trace metal contamination and accumulation in sediment and plants of the suoxu river, China. Aquat. Bot. 140, 92-95.

Kabata-Pendias, A., 2011. Trace Elements in Soils and Plants, 4th ed. CRC Press, pp. 123-401.

Krishnakumar, S., Ramasamy, S., Chandrasekar, N., Peter, T.S., Godson, P.S., Gopal, V., Magesh, N.S., 2016. Spatial risk assessment and trace element concentration in reef associated sediments of Van Island, southern part of the Gulf of Mannar, India. Mar. Pollut. Bull. 115, 444-450.

Kumari, A., Panda, R., Jha, M.K., Kumar, J.R., Lee, J.Y., 2015. Process development to recover rare earth metals from monazite mineral: a review. Miner. Eng. 79, 102-115.

Lee, K., Hur, S.D., Hou, S., Burn-Nunes, L.J., Hong, S., Barbante, C., Boutron, C.F., Rosman, K.J.R., 2011. Isotopic signatures for natural versus anthropogenic $\mathrm{Pb}$ in high-altitude Mt. Everest ice cores during the past 800 years. Sci. Total Environ. 412-413, 194-202.

Li, H., Ji, H., 2017. Chemical speciation, vertical profile and human health risk assessment of heavy metals in soils from coal-mine brownfield, Beijing, China. J. Geochem. Explor. 183, 22-32.

Liang, Z., Ding, Q., Wei, D., Li, J., Chen, S., Ma, Y., 2013. Major controlling factors and predictions for cadmium transfer from the soil into spinach plants. Ecotoxicol. Environ. Saf. 93 (4), 180-185.

Liu, B., Ai, S., Zhang, W., Huang, D., Zhang, Y., 2017a. Assessment of the bioavailability, bioaccessibility and transfer of heavy metals in the soil-grain-human systems near a mining and smelting area in NW China. Sci. Total Environ. 609, 822-829.

Liu, J.-J., Ni, Z.-X., Diao, Z.-H., Hu, Y.-X., Xu, X.-R., 2018. Contamination level, chemical fraction and ecological risk of heavy metals in sediments from Daya Bay, South China Sea. Mar. Pollut. Bull. 128, 132-139.

Liu, K., Lv, J., He, W., Zhang, H., Cao, Y., Dai, Y., 2015. Major factors influencing cadmium uptake from the soil into wheat plants. Ecotoxicol. Environ. Saf. 113, 207-213.

Liu, Y., Du, Q., Wang, Q., Yu, H., Liu, J., Tian, Y., Chang, C., Lei, J., 2017b. Causal inference between bioavailability of heavy metals and environmental factors in a large-scale region. Environ. Pollut. 226, 370-378.

Loell, M., Albrecht, C., Felix-Henningsen, P., 2011. Rare earth elements and relation between their potential bioavailability and soil properties, Nidda catchment (Central Germany). Plant Soil 349, 303-317.

Luo, J., Tang, R., She, J., Chen, Y., Gong, Y., Zhou, J., Yu, D., 2013. The chromium in timberline forests in the eastern Tibetan Plateau. Environ. Sci. Proc. Impacts 15 (10), 1930-1937.

Luo, J., She, J., Yang, P., Sun, S., Li, W., Gong, Y., Tang, R., 2014. Heavy metal concentrations in timberline trees of eastern Tibetan Plateau. Ecotoxicology 23, 1086-1098.

Maanan, M., Zourarah, B., Carruesco, C., Aajjane, A., Naud, J., 2004. The distribution of heavy metals in the Sidi Moussa lagoon sediments (Atlantic Moroccan Coast). J. Afr. Earth. Sci. 39, 473-483.

Magesh, N.S., Chandrasekar, N., Elango, L., 2017. Trace element concentrations in the groundwater of the Tamiraparani river basin, South India: insights from human health risk and multivariate statistical techniques. Chemosphere 185, 468-479.

Mamat, Z., Haximu, S., Zhang, Z., Aji, R., 2016. An ecological risk assessment of heavy metal contamination in the surface sediments of Bosten Lake, northwest China. Environ. Sci. Pollut. Res. 23, 7255-7265.

Mao, Z., Fu, H., Nan, Z., Wan, C., 2015. Fatty acid, amino acid, and mineral composition of four common vetch seeds on Qinghai-Tibetan Plateau. Food Chem. 171, 13-18.

Milićević, T., Relić, D., Škrivanj, S., Tešić, Ž., Popović, A., 2017. Assessment of major and trace element bioavailability in vineyard soil applying different single extraction procedures and pseudo-total digestion. Chemosphere 171, 284-293.

Ministry of Environmental Protection of the People's Pepubic of China (MEPC), 1990. Background values of soil elements in China. China Environment Science Press, pp. 329-493.

Müller, G., 1969. Index of geo-accumulation in sediments of the Rhine River. GeoJournal 2 (3), 108-118.

Park, J.-H., Choi, K.-K., 2013. Risk assessment of soil, water and crops in abandoned Geumryeong mine in South Korea. J. Geochem. Explor. 128, 117-123.

Ramachandra, T.V., Sudarshan, P.B., Mahesh, M.K., Vinay, S., 2018. Spatial patterns of heavy metal accumulation in sediments and macrophytes of Bellandur wetland, Bangalore. J. Environ. Manag. 206, 1204-1210.

Seshan, B.R.R., Natesan, U., Deepthi, K., 2010. Geochemical and statistical approach for evaluation of heavy metal pollution in core sediments in southeast coast of India. Int. J. Environ. Sci. Technol. 7 (2), 291-306.

Shao, J., Shi, J., Duo, B., Liu, C., Gao, Y., Fu, J., Yang, R., Jiang, G., 2016. Mercury in alpine fish from four rivers in the Tibetan Plateau. J. Environ. Sci. -China 39, 22-28.

Shen, M., Chen, L., Han, W., Ma, A., 2018. Methods for the determination of heavy metals in indocalamus leaves after different preservation treatment using inductively-coupled plasma mass spectrometry. Microchem. J. 139, 295-300.

Tang, R., Luo, J., Yang, P., She, J., Chen, Y., Gong, Y., Zhou, J., 2014. Trace metals of needles and litter in timberline forests in the Eastern of Tibetan Plateau, China. Ecol. Indic. 45 (5), 669-676.

Wang, G., Yan, X., Zhang, F., Zeng, C., Gao, D., 2014a. Traffic-related trace element accumulation in roadside soils and wild grasses in the Qinghai-Tibet Plateau, China. Int. J. Environ. Res. Public Health 11, 456-472.

Wang, J., Liu, R., Zhang, P., Yu, W., Shen, Z., Feng, C., 2014b. Spatial variation, environmental assessment and source identification of heavy metals in sediments of the Yangtze River Estuary. Mar. Pollut. Bull. 87, 364-373.

Wu, J., Duan, D.P., Lu, J., Luo, Y.M., Wen, X.H., Guo, X.Y., Boman, B.J., 2016. Inorganic pollution around the Qinghai-Tibet Plateau: an overview of the current observations. Sci. Total Environ. 550, 628-636.

Wu, J., Lu, J., Li, L., Min, X., Luo, Y., 2018a. Pollution, ecological-health risks, and sources of heavy metals in soil of the northeastern Qinghai-Tibet Plateau. Chemosphere 201, 234-242.

Wu, J., Lu, J., Li, L., Min, X., Zhang, Z., Luo, Y., 2018b. Distribution, pollution, and ecological risks of rare earth elements in soil of the northeastern Qinghai-Tibet Plateau. Hum. Ecol. Risk Assess. https://doi.org/10.1080/10807039.2018.1475215.

Xie, H., Li, J., Zhang, C., Tian, Z., Liu, X., Tang, C., Han, Y., Liu, W., 2014. Assessment of heavy metal contents in surface soil in the Lhasa-Shigatse-Nam Co area of the Tibetan Plateau, China. Bull. Environ. Contam. Toxicol. 93, 192-198.

Xu, X., Cao, Z., Zhang, Z., Li, R., Hu, B., 2016. Spatial distribution and pollution assessment of heavy metals in the surface sediments of the Bohai and Yellow Seas. Mar. Pollut. Bull. 110 (1), 596-602.

Yan, X., Zhang, F., Gao, D., Zeng, C., Xiang, W., Zhang, M., 2013. Accumulations of heavy metals in roadside soils close to zhaling, eling and nam co lakes in the Tibetan Plateau. Int. J. Environ. Res. Public Health 10, 2384-2400.

Yang, R., Jing, C., Zhang, Q., Wang, Z., Wang, Y., Li, Y., Jiang, G., 2011. Polybrominated diphenyl ethers (PBDEs) and mercury in fish from lakes of the Tibetan Plateau. Chemosphere 83, 862-867.

Yang, Y., Chen, W., Wang, M., Li, Y., Peng, C., 2017. Evaluating the potential health risk of toxic trace elements in vegetables: accounting for variations in soil factors. Sci. Total Environ. 584-585, 942-949.

Zhang, H., Zhang, Y., Wang, Z., Ding, M., Jiang, Y., Xie, Z., 2016. Traffic-related metal (loid) status and uptake by dominant plants growing naturally in roadside soils in the Tibetan Plateau, China. Sci. Total Environ. 573, 915-923.

Zhang, Q., Kang, S., Kaspari, S., Li, C., Qin, D., Mayewski, P.A., Hou, S., 2009. Rare earth elements in an ice core from Mt. Everest: seasonal variations and potential sources. Atmos. Res. 94, 300-312.

Zhang, Z., Wang, Q., Zheng, D., Zheng, N., Lu, X., 2010. Mercury distribution and bioaccumulation up the soil-plant-grasshopper-spider food chain in Huludao city, China. J. Environ. Sci. 22 (8), 1179-1183. 